\title{
Biomonitoring organotin pollution with gastropods and mussels
}

\author{
J. M. Ruiz ${ }^{1, *}$, R. Barreiro ${ }^{1}$, J. J. González ${ }^{2}$ \\ ${ }^{1}$ Depto. BA, BV y Ecología, Universidade da Coruña, Campus da Zapateira s/n, 15071 Coruña, Spain \\ ${ }^{2}$ Instituto Español de Oceanografía, Apdo. 1552, 36280 Vigo, Spain
}

\begin{abstract}
In order to compare their performance for the biomonitoring of organotin (OT) pollution, Galician (NW Spain) populations of gastropods Nassarius reticulatus and mussels Mytilus galloprovincialis were sampled in 2000. Imposex (a set of sexual anomalies) in snails as well as the bioaccumulation of several OT species (mainly tributyltin [TBT]) in both invertebrates were determined. Imposex was related to TBT in female gastropod tissues in a biphasic manner, the slope changing

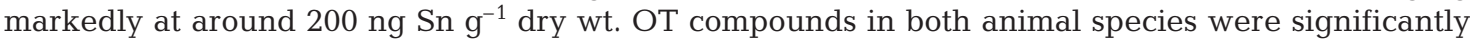
correlated, mussels consistently accumulating more than gastropods; in addition, correlation coefficients considerably increased when outliers were excluded from computation with the aid of fine chemical speciation analyses. The expected decline of OT pollution can satisfactorily be recorded by means of monitoring concentrations in either mussels and/or gastropods. However, the use of the latter is favoured because their imposex response is an easily determined biomarker, which additionally provides useful insights into the biological impact of TBT.
\end{abstract}

KEY WORDS: Biomonitoring - Organotin pollution - Tributyltin · TBT · Imposex - Gastropod · Nassarius reticulatus $\cdot$ Mussel $\cdot$ Mytilus galloprovincialis $\cdot$ Bioaccumulation

\section{INTRODUCTION}

The environmental history of tributyltin (TBT, an organometallic compound commonly used as a biocide in antifouling ship bottom paints) extends over the last 4 decades (e.g. Ruiz et al. 1996). As a total prohibition on TBT application took effect on 1st January 2003 from the International Maritime Organisation (IMO) (see http://www.imo.org), TBT uses should have halted; however, the effectiveness of such a measure remains to be seen since global market forces will play a role (Champ 2000). Thus, although there is still room for new findings on the environmental impact of organotins (OTs), efforts in developed countries are currently concentrated on recording the expected decline of TBT in their coastal waters. For instance, the OSPAR Convention for the Protection of the Marine Environment of the NE Atlantic (signed and ratified by 15 states plus the Commission of the European Com- munities, CEC) has included OT as the 5th set of pollutants for mandatory monitoring to coincide with the IMO ban (see http://www.ospar.org).

OSPAR compulsory vigilance studies for other contaminants (i.e. heavy metals, polychlorinated biphenyls [PCBs], polycyclic aromatic hydrocarbons [PAHs] and nutrients) mostly consist of registering concentrations in biota (generally mussels) and sediments. For TBT, though, signatory countries not only have to monitor its levels in gastropod molluscs but also, for the first time ever, the incidence of some specific biological effects. These mainly refer to a set of male sexual characteristics (penis included) which are superimposed by TBT onto female gastropods (i.e. imposex, e.g. Smith 1971, Gibbs \& Bryan 1996). Imposex coastal monitoring focuses on Nucella lapillus (L.), but Nassarius reticulatus (L.) has been suggested as a suitable alternative for southern OSPAR areas; other than its wider distributional range, the latter gastropod has recognised ad- 
vantages such as its presence in soft bottoms, its tolerance of brackish waters and its moderate sensitivity to TBT (Stroben et al. 1992b, Bryan et al. 1993, Huet et al. 1995). Indeed, N. reticulatus has recently been used to assess OT pollution at these latitudes at both national (Barroso et al. 2002a) and more local (Barreiro et al. 2001) scales.

The question as to whether the benefits from using gastropods for the routine monitoring of TBT outweigh those from using mussels has not, however, been purposely addressed. While the latter are renowned bioaccumulators of contaminants (for a global summary of mussel-watch TBT data, see e.g. Sudaryanto et al. 2002), the former can also build up considerable OT concentrations in tissues, which, in addition, are related in a dose-response manner to imposex (see references above). Consequently, the present work was carried out in order to compare the TBT biomonitoring performance of both sets of invertebrates, and thus assist the design of desirable OT vigilance programmes worldwide.

\section{MATERIALS AND METHODS}

Gastropods. Twenty-six sites distributed through the 7 most important rias (estuaries formed by drowned river valleys) in the Atlantic facade of Galicia (NW
Spain, see Fig. 1) were visited during the late winter months (February to March) of 2000. Gastropods Nassarius reticulatus were collected by hand during low tide, each sample consisting of at least 30 of the largest specimens. Samples were depurated in aquaria (18 psu artificial seawater, $12 \pm 1^{\circ} \mathrm{C}$ ) for $48 \mathrm{~h}$ prior to imposex assessment, which proceeded following Stroben et al. (1992b) as detailed in Barreiro et al. (2001). Later, opercula were removed and each sex was pooled per site in vials that were kept frozen until the chemical analysis of female tissues (see below).

Three indices have been mainly used to gauge imposex in this species: the relative penis length index (RPLI per site: mean length of female penis as a percentage of that of males), the vas deferens sequence index (VDSI: the stage in the development of male structures on females), and the average oviduct stage (AOS: the degree of oviduct convolution). The RPLI is the simplest of them all, the most agreed, and the one bearing the strongest correlation to TBT concentrations in tissues. The VDSI displays a similar relation to $\mathrm{TBT}_{i}$ however, there is some disagreement with respect to both the expression and the computation of its most advanced stage (VDSI $4^{+}$has been assigned numerical values of $4,4.5$ and 5, respectively in Stroben et al. 1992b, Barreiro et al. 2001 and Barroso et al. 2002a). Finally, the AOS has been proposed by Barreiro et al. (2001) to improve the ranking of severely polluted sites; however, Barroso et al. (2002a) did not observe advantages in this respect. Further investigations are needed to accord the use of these last 2 indices, and also to firmly validate their relationship with female sterility. Thus, bearing in mind the main objective of this work, the data pertaining to both VDSI and AOS will be dealt with elsewhere, and only those for RPLI are reported here.

Mussels. Native wild mussels Mytilus galloprovincialis (Lmk.) were collected in 2000 from nearby intertidal rocks in 18 of the 26 gastropod sites. The season (early autumn) and the sampling and pre-treatment procedure followed the guidelines established by OSPAR and applied by the Instituto Español de Oceanografía since the early 1990s (e.g. Besada et al. 2002). In summary, more than 50 individuals were collected to fit in each of 4 equidistant shell length classes (mm): 35 to 40,41 to 46,47 to 53 and 54 to 61 . Following $24 \mathrm{~h}$ depuration in water from the sampling area, their soft parts were removed per class, later
Fig. 1. Mytilus galloprovincialis and Nassarius reticulatus. Location of sampling sites The 3 largest coastal conurbations in the study area are shaded dark grey 
all pooled and homogenised, and finally freeze-dried until analyses.

OT analysis. The concentration of OT species (monobutyltin [MBT], dibutyltin [DBT], tributyltin [TBT] and triphenyltin [TPhT]) was determined in every reported sample. The analyses were performed in a blind manner by the Laboratoire de Chimie Analytique Bio-Inorganique et Environnement (LCABIE, UMR 5034 CNRS-Université de Pau et des Pays de l'Adour, Pau, France), a laboratory routinely participating in the production of OT Certified Reference Materials (CRMs) for the CEC's Bureau of Community References (BCR). The protocol used followed Szpunar et al. (1996) with improvements detailed in Svavarsson et al. (2001); the quantification limit (ng Sn $\mathrm{g}^{-1}$ fresh wt) is, thus, now established at 1.0 for both TBT and DBT, 1.5 for MBT and 3.0 for TPhT (use a factor of 5 to convert to dry wt). In summary, the analytical protocol for the samples included tripropyltin as an internal standard, solubilisation with tetramethylammonium hydroxide (TMAH) in a low power microwave field, ethylation in a solution of sodium tetraethylborate $\left(\mathrm{NaBEt}_{4}\right)$, and extraction to isooctane. Detection of the ethylated OT species was accomplished with a GC-AED (gas chromatograph-atomic emission detector) system equipped with a split/splitless injection port and an automatic sampler.

The procedure was validated using 2 BCR CRMs: the Mussel 477 tissue $\left(1.50 \pm 0.28 \mathrm{mg} \mathrm{kg}^{-1}\right.$ as MBT cations, $1.54 \pm 0.12 \mathrm{mg} \mathrm{kg}^{-1}$ as DBT cations, and $2.20 \pm 0.19 \mathrm{mg}$ $\mathrm{kg}^{-1}$ as TBT cations, all in dry wt), and the Oyster 710 tissue $\left(0.082 \pm 0.015 \mathrm{mg} \mathrm{kg}^{-1}\right.$ as DBT species, $0.133 \pm$ $0.019 \mathrm{mg} \mathrm{kg}^{-1}$ as TBT species, both in dry wt). The recoveries of the former (used with gastropod samples) were $93.3 \pm 12.7 \%$ for $\mathrm{MBT}, 103.9 \pm 7.8 \%$ for $\mathrm{DBT}$, and $101.2 \pm 7.7 \%$ for $\mathrm{TBT}$, and the recoveries of the latter (used with mussel samples) were $113.4 \pm 12.2 \%$ for DBT, and $106.8 \pm 6.8 \%$ for TBT. The concentration obtained for every OT is reported here as mean $\mathrm{ng} \mathrm{Sn} \mathrm{g}^{-1}$ dry wt (ppb Sn DW). The values are analytical means, their CV (or relative standard deviation) never surpassing $10 \%$ except for MBT in some mussel samples.

The normal distribution of data sets was checked prior to establishing the statistical relationships between them; the significance levels are depicted below as ${ }^{*},{ }^{* *}$ and ${ }^{* * *}$, respectively, for $\mathrm{p}<0.05, \mathrm{p}<$ 0.01 and $\mathrm{p}<0.001$.

\section{RESULTS}

\section{Imposex}

All the 545 female Nassarius reticulatus examined for this study exhibited a penis, the size of which (in terms of RPLI) ranged from 15 to $96 \%$ of that of the corresponding males (Table 1). Half of the populations were severely affected by imposex (RPLI > $75 \%$ ), and were generally located in the upstream reaches of the industrial rias of Ferrol, A Coruña and Vigo; however, they also included other samples such as those taken within a marina and near a shipyard (Sites 3 and 11, respectively). On the other hand, only 4 populations belonging to mussel-culturing rias (Betanzos, Muros and Arousa) were mildly affected (RPLI $<25 \%$ ).

\section{OT bioaccumulation}

OT concentrations found in female gastropod tissues are shown in Table 2. While TPhT could not be detected in any sample, the 3 butyltin species were ubiquitous (except MBT which could not be quanti- 
Table 2. Nassarius reticulatus and Mytilus galloprovincialis. Biomonitoring OT pollution. Mean butyltin concentration (ng Sn g ${ }^{-1} \mathrm{DW}$ ) in tissues of gastropods and mussels. MBT: monobutyltin; DBT: dibutyltin; TBT: tributyltin; $\Sigma$ BTs: total butyltins; nq: not quantifiable. See Table 1 for site names

\begin{tabular}{|c|c|c|c|c|c|c|c|c|}
\hline \multirow[b]{2}{*}{ Site } & \multirow{2}{*}{$\overline{\mathrm{MBT}}$} & \multicolumn{3}{|c|}{ Gastropods - } & \multirow[b]{2}{*}{$\mathrm{MBT}$} & \multicolumn{2}{|c|}{ Mussels- } & \multirow[b]{2}{*}{$\Sigma \mathrm{BTs}$} \\
\hline & & DBT & TBT & $\Sigma \mathrm{BTs}$ & & DBT & ТВТ & \\
\hline 1 & 213 & 475 & 643 & 1332 & 356 & 1510 & 1286 & 3151 \\
\hline 2 & 54 & 256 & 547 & 857 & 196 & 708 & 1011 & 1915 \\
\hline 3 & 29 & 353 & 479 & 862 & 697 & 1961 & 1177 & 3835 \\
\hline 4 & 9 & 74 & 83 & 166 & 65 & 213 & 281 & 558 \\
\hline 5 & 58 & 172 & 137 & 367 & 111 & 370 & 336 & 817 \\
\hline 6 & 145 & 409 & 614 & 1168 & 376 & 1254 & 1011 & 2641 \\
\hline 7 & 136 & 363 & 549 & 1047 & - & - & - & - \\
\hline 8 & 393 & 842 & 856 & 2090 & 1243 & 2094 & 1856 & 5193 \\
\hline 9 & $\mathrm{nq}$ & 48 & 83 & 132 & - & - & - & - \\
\hline 10 & 11 & 87 & 101 & 199 & 9 & 121 & 155 & 286 \\
\hline 11 & 263 & 497 & 373 & 1132 & 75 & 447 & 470 & 992 \\
\hline 12 & 8 & 65 & 120 & 192 & 122 & 396 & 342 & 860 \\
\hline 13 & $\mathrm{nq}$ & 76 & 124 & 201 & - & - & - & - \\
\hline 14 & 18 & 181 & 230 & 429 & - & - & - & - \\
\hline 15 & $\mathrm{nq}$ & 44 & 104 & 150 & 51 & 175 & 221 & 447 \\
\hline 16 & 9 & 63 & 62 & 134 & - & - & - & - \\
\hline 17 & 16 & 64 & 48 & 128 & 15 & 143 & 238 & 397 \\
\hline 18 & $\mathrm{nq}$ & 134 & 188 & 323 & 71 & 391 & 949 & 1411 \\
\hline 19 & 75 & 182 & 289 & 545 & 195 & 594 & 907 & 1696 \\
\hline 20 & 9 & 113 & 168 & 290 & - & - & - & - \\
\hline 21 & $\mathrm{nq}$ & 159 & 319 & 480 & 108 & 395 & 583 & 1087 \\
\hline 22 & 30 & 117 & 126 & 273 & - & - & - & - \\
\hline 23 & 73 & 189 & 185 & 448 & 120 & 704 & 1065 & 1888 \\
\hline 24 & 37 & 312 & 380 & 729 & - & - & - & - \\
\hline 25 & 15 & 76 & 72 & 163 & 70 & 383 & 409 & 862 \\
\hline 26 & 72 & 137 & 125 & 335 & 217 & 800 & 783 & 1800 \\
\hline
\end{tabular}

fied at 5 sites). Their total ( $\Sigma \mathrm{BT}$ ) ranged from 128 to 2090 ppb Sn DW, TBT being predominant in 19 of the 26 samples (mean of $52 \pm 10 \%$ of $\Sigma$ BTs). The linear correlation that could be established between TBT and both DBT $\left(\mathrm{r}=0.92^{* * *}\right)$ and $\operatorname{MBT}\left(\mathrm{r}=0.78^{* * *}\right.$, undetectable concentrations taken as 1 ppb Sn DW) denote a common origin for OT pollution in the region (i.e. the use of antifouling paints with the parent compound TBT included as a biocide). Given the causative link between TBT and imposex, the geographical pattern of the biological effect described above closely agrees with that of OT bioaccumulation. The correlation between both data sets was, thus, strong; the best correlation $\left(\mathrm{r}=0.87^{* * *}\right)$ was found when plotting ln TBT versus RPLI. However, the relationship between these 2 parameters (Fig. 2) is better described as biphasic: a sharp rise of RPLI to reach $80 \%$ for TBT below $200 \mathrm{ppb}$ Sn DW ( $\mathrm{r}=0.78^{* * *}, \mathrm{n}=15$ ) followed by some further increase but with a much lower slope for TBT levels up to 4 times higher ( $\mathrm{r}=$ $0.64^{*}, \mathrm{n}=11$ ).

OT concentrations found in tissues of mussels Mytilus galloprovincialis are also summarised in Table 2. As with gastropods, 3 butyltin species were detected in every sample, while no TPhT was found. $\Sigma$ BTs ranged from 286 to $5193 \mathrm{ppb}$ Sn DW, TBT being predominant in 11 of the 18 samples (mean of $48 \pm 9 \%$ of $\Sigma \mathrm{BTs}$ ) and correlating with both DBT $\left(\mathrm{r}=0.88^{* * *}\right)$ and MBT $\left(\mathrm{r}=0.82^{* * *}\right)$. The geographical pattern of TBT in samples concords with that for gastropods (and therefore with RPLI values too): the half most contaminated (TBT at 800 ppb Sn DW and above) came from industrialised areas, while only 4 populations belonging to mussel-culturing rias showed TBT below 300 ppb Sn DW.

Butyltins in both invertebrates were significantly correlated on a per chemical species basis, mussels consistently accumulating more than gastropods; coefficients ranged from 0.70 for MBT (undetectable concentrations in gastropods taken as 1 ppb Sn DW) to 0.86 for $\Sigma$ BTs (all $\mathrm{n}=18$ and at ${ }^{* * *}$ but MBT at ${ }^{* *}$ ). Interestingly, the graphical representation of data sets for MBT, DBT and $\mathrm{BTTS}$ (but not for TBT) revealed 2 apparent outliers (Fig. 3). These deviated points correspond to the 2 samples above taken within a marina and near a shipyard (Sites 3 and 11, respectively), and eliminating them from computation considerably increased 3 coefficients (12\% for $\Sigma$ BTs, $18 \%$ for DBT and $36 \%$ for MBT) but only marginally increased $(2 \%)$ that for TBT (all $n=16$ and at ${ }^{* * *}$, see Fig. 3 ).

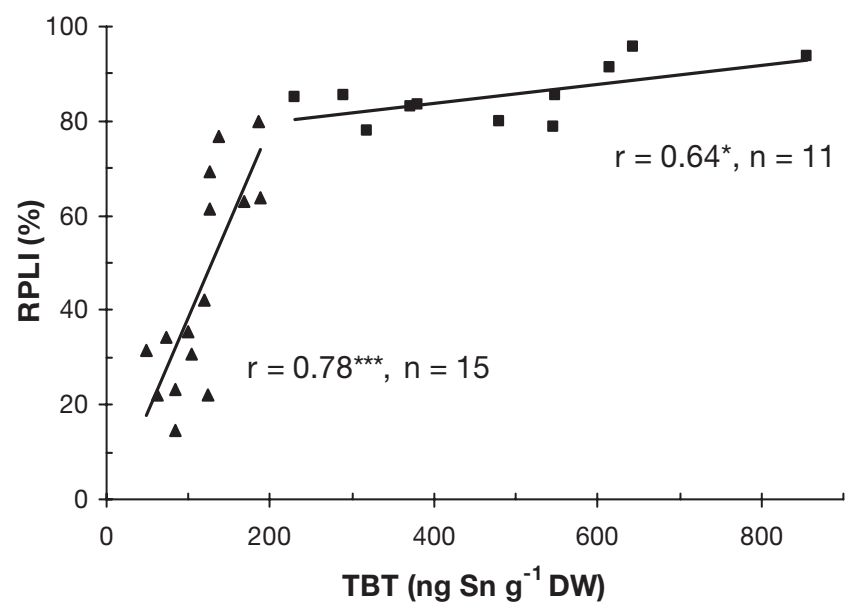

Fig. 2. Nassarius reticulatus. Relative penis length index (RPLI, \%) versus tributyltin (TBT, ng Sn ${ }^{-1}$ DW) in tissues 

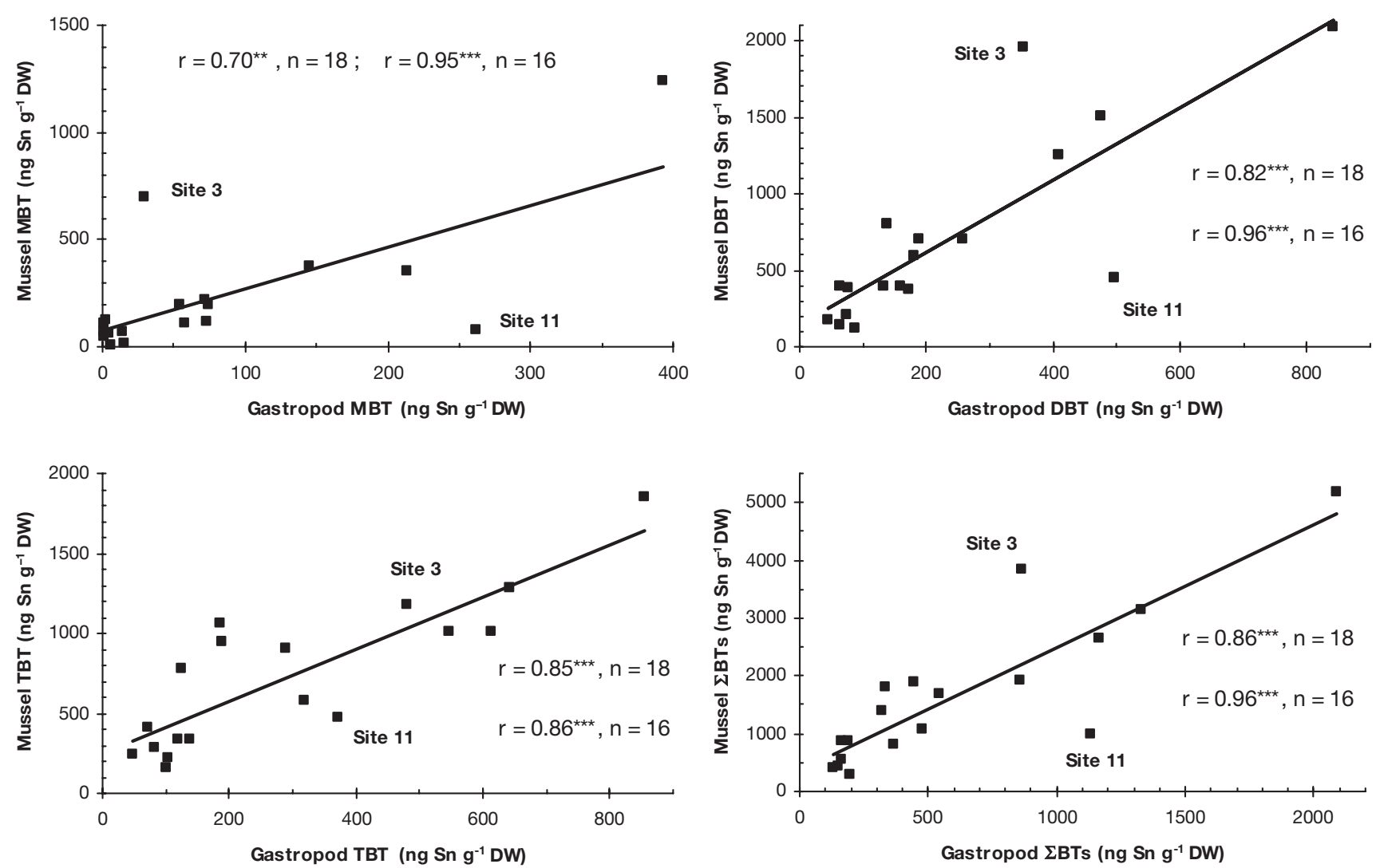

Fig. 3. Mytilus galloprovincialis and Nassarius reticulatus. Butyltins (MBT, DBT, TBT and $\Sigma$ BTs, all in ng Sn $\mathrm{g}^{-1} \mathrm{DW}$ ) in mussels versus gastropods

\section{DISCUSSION}

\section{Bioaccumulation}

The degree of TBT contamination at a particular coastal site is dependent on multiple processes (input characteristics, hydrodynamics, distribution among phases, deposition/resuspension, degradation rates, etc.) and is, therefore, largely site-specific (e.g. Ruiz et al. 1996). Its assessment typically relies on biomonitoring approaches, and this work shows that the use of the 2 contrasting invertebrates above renders the same regional picture both in terms of pollution spread and extent. Indeed, it is notable that a close match such as that in Fig. 3 can be obtained despite (1) the separated sampling seasons, (2) the distinct ecology of these 2 molluscs, and (3) the wide range of environmental scenarios considered.

The first hurdle could not be avoided because the reproductive cycle of each species defines the best sampling season: for Nassarius reticulatus, it is around spring time when sexual characters are clearly identifiable, and early autumn is the appropriate prespawning period in the area for Mytilus galloprovincialis (Besada et al. 2002). However, Fig. 3 indicates that even if there is some input seasonality (probably not widespread because pleasure boating is not popular in the region, see Ruiz et al. 1998), it is overcome by the combined use of biomonitors which, by definition, are time-integrators of ambient pollutants. The second obstacle stems from the contrast between the ecology of the mussel (a rocky bottom filter feeder) and the gastropod (a sediment-dwelling detritivore), a disparity that leads to the presumption of different routes of uptake and diverging OT tissue loads. The former belief seems to hold since Pope (1998) demonstrated that $N$. reticulatus acquires TBT in the same proportion from both water and sediments, while incorporation in mussels occurs predominantly through the ingestion of phytoplankton (Laughlin et al. 1986). On the contrary, OT body burdens in both species are fairly convergent. Fig. 3, thus, constitutes a prime confirmation of the contention by Laughlin (1996) that biomonitors likely reflect the steady-state distribution of TBT in all compartments of the ecosystem rather than the concentration in a single one.

Finally, the third problem could well have been bypassed by considering only those populations under the influence of similar types of TBT inputs, but then the exercise would have been of limited relevance. In 
the first instance, pollution at a given locality should be at a steady-state distribution among the diverse ecosystem compartments, yet subject to possible perturbations affecting them, at least transiently. Perturbations may be anthropogenic such as coastal public works (with effects usually at a local scale) or natural such a drought (often affecting much larger scales, e.g. Ruiz \& Saiz Salinas 2000). Since there are TBT-polluting human activities that are clearly less regular in time than others, it is hereafter contended that some perturbations of this type are responsible for the departure of Sites 3 and 11 from the general trend of MBT, DBT, and $\Sigma$ BTs in Fig. 3.

On the one hand, Site 3 is a marina lately promoted by local authorities. While gastropods there contained each butyltin species at proportions (with respect to $\Sigma$ BTs) around the average for the 26 sites, their percentages in the mussel were the minimum (TBT), the maximum (DBT) and the second highest (MBT) of all the sites. In addition, the absolute values for both degradation products in Site 3 mussels are second only to those in Site 8 (see Table 2). It seems then that some particular perturbation distorted, both in absolute and relative terms, the normal OT bioaccumulation pattern in mussels but not in gastropods. Probably, some dredging operations around the summer yachting time resuspended the deep sediments (where derivatives prevail over the parent compound, see Sarradin et al. 1995) which were subsequently incorporated by the active suspension feeding characteristic of the mussel.

On the other hand, Site 11 is under the influence of a ship maintenance facility. There, TBT in Nucella lapillus in 1996 (see Ruiz et al. 1998) reached 974 ppb Sn DW, with $\Sigma$ BTs proportions at $54 \%$ (TBT), $36 \%$ (DBT) and $10 \%(\mathrm{MBT})$. In the present work, mussels (the favourite prey of $N$. lapillus) at Site 11 show the same decreasing order for $\Sigma$ BTs proportions, absolute $N$. lapillus values in summer 1996 doubling those for mussels in autumn 2000. This suggests that the fresh TBT input around Site 11 decreased between those years, and that OT contents and proportions in the mussels have accommodated to the new situation. On the contrary, at the beginning of 2000 at Site 11, Nassarius reticulatus displayed a markedly different proportional accumulation pattern, with TBT the lowest of the current 26 data set at $33 \%$ of $\Sigma$ BTS, DBT above the average value at $44 \%$, and MBT the top of the series at $23 \%$. Thus, it appears that a considerable fraction of the reduction of TBT pollution at this site occurred shortly before the collection of the gastropod, which by that sampling date had not had enough time to equilibrate the TBT sequential metabolism with respect to the new ambient concentrations (but there are no data on the activity of the shipyard).

\section{Biological effects}

Imposex in natural gastropod populations is a result of OT pollution from antifouling paints. This was conclusively shown for Nucella lapillus (e.g. Bryan et al. 1986, Gibbs \& Bryan 1986) and also for Nassarius reticulatus after both field (Stroben et al. 1992b, Bryan et al. 1993, Huet et al. 1995, Barreiro et al. 2001, Barroso et al. 2002a) and laboratory (Stroben et al. 1992a, Bettin et al. 1996, Barroso et al. 2002b) studies. The present work adds to this database with a regional survey, where the relationship between RPLI and TBT (Fig. 2) is similar to that described in those previous reports. For instance, both Bryan et al. (1993) (data for pre-restriction years 1985-87) and Barroso et al. (2002a) also found a sharp RPLI increase for TBT up to around 200 ppb Sn DW. At higher concentrations, however, while data in Barroso et al. (2002a) tended to a plateau at approximately $85 \%$ for TBT up to $1400 \mathrm{ppb}$ Sn DW, the few pre-restriction data in Bryan et al. (1993) suggest a positive slope up to $500 \mathrm{ppb} \mathrm{Sn}$ DW, which is now confirmed to be significant over an even wider TBT range.

Although all authors agree on the value of imposex in Nassarius reticulatus for biomonitoring TBT pollution, special attention must be paid to Bryan et al. (1993) since this work includes observations on the effect of the 1987 UK restrictions on TBT usage. There, it is shown that RPLI data (sets for 1989-90 and 1991 to 1993) become shifted to the left as tissue TBT levels decline markedly following the 1987 partial ban, while the vertical range of RPLI is only slightly reduced; the latter occurs because the decrease of female penislengths is slowed by environmental (TBT takes longer to decline in sediments than in water) and mostly biological factors (low, if any, reversibility rate of imposex, longevity of individuals and limited recruitment into populations). Bryan et al. (1993), therefore, concluded that when environmental TBT concentrations decline fairly rapidly, analysis of $N$. reticulatus tissues provides a better indication of change than measurements of population imposex. Even if this recommendation must be born in mind, modern monitoring programmes such as those within OSPAR need to establish confident links between contaminant inputs, environmental concentrations and biological effects.

While considerable knowledge has been gained over the last few decades on pollution effects at all levels in the biological hierarchy (particularly at the bottom ones, e.g. Porte et al. 2002), in no case has research provided tools as valuable as imposex for TBT. For instance, tissue residue chemistry data have been adequately construed in terms of some physiological measurement of stress in mussels (Widdows et al. 1995), yet the potential of this procedure has not 
resulted in its common application in vigilance schemes. Possible reasons for this are also applicable to most other candidate techniques, namely the lack of both sensitivity and specificity of the biological response. Thus, the toxicological interpretation of present mussel data according to the tissue residue approach would lead to the conclusion that, while TBT exceeds the threshold of effects on respiratory uncoupling (0.2 $\mu \mathrm{g} \mathrm{TBT}^{-1}$ DW or, approximately, $80 \mathrm{ppb} \mathrm{Sn}$ DW) in every population, only 1 surpasses that of severely inhibited scope for growth $\left(4 \mu \mathrm{g} \mathrm{TBT}^{-1} \mathrm{DW}\right.$ or $1600 \mathrm{ppb}$ Sn DW). In addition, if in the future laboratory experiments were to show such detrimental effects in local mussels, many other individual pollutants (or pollutant families if QSARs were employed, see Widdows et al. 1995) would have to be invoked in order to assign responsibilities for the observations.

Finally, it is not known how quickly ambient TBT levels are expected to drop, in the OSPAR area and elsewhere, following the IMO total prohibition. Other than the sediment legacy problem (e.g. Svavarsson et al. 2001), the previous partial ban in European coastal waters appears to have taken more rapid effect in the UK than in other countries such as France (issued in 1982, e.g. Huet et al. 1995, Michel \& Averty 1999), Portugal and Spain (both adopting the 1989 CEC directive in the early 1990s, e.g. Barroso \& Moreira 2002 and Ruiz et al. 1998, respectively). In any case, the valuable caveat above (Bryan et al. 1993) should not deter research on this paradigmatic example of the biological effects of pollution. Rather, it ought to spur further and detailed investigations on the biology and population dynamics of Nassarius reticulatus in response to TBT, so that its monitoring utility can be refined.

\section{CONCLUSIONS}

Environmental vigilance programmes are needed to follow up the expected decline of global marine pollution subsequent to the IMO total ban on the application of TBT antifouling paints. In the OSPAR maritime area, TBT concentrations in coastal waters can adequately be monitored by means of either mussels such as Mytilus galloprovincialis and/or gastropods such as Nassarius reticulatus since both invertebrates perform equally well. Their concomitant use is indeed recommended because their distinct ecology, combined with up to date chemical speciation protocols, can assist in understanding the particularities of contamination at specific sites. However, when financial or other constraints apply, the use of gastropods is favoured because their imposex response is an easily determined biomarker, which additionally provides useful insights into the biological impact of TBT.
Acknowledgements. This work was partially funded by JACUMAR (Junta Nacional Asesora de Cultivos Marinos) and MCyT (Project Ref. REN2001-0899/MAR). We thank I. González and M. Quintela for their help with field and laboratory work.

\section{LITERATURE CITED}

Barreiro R, González R, Quintela M, Ruiz JM (2001) Imposex, organotin bioaccumulation and sterile females in Nassarius reticulatus from polluted areas of NW Spain. Mar Ecol Prog Ser 218:203-212

Barroso CM, Moreira MH (2002) Spatial and temporal changes of TBT pollution along the Portuguese coast: inefficacy of the EEC directive 89/677. Mar Pollut Bull 44:480-486

Barroso CM, Moreira MH, Bebianno MJ (2002a) Imposex, female sterility and organotin contamination of the prosobranch Nassarius reticulatus (L.) from the Portuguese coast. Mar Ecol Prog Ser 230:127-135

Barroso CM, Reis-Henriques MA, Ferreira MS, Moreira MH (2002b) The effectiveness of some compounds derived from antifouling paints in promoting imposex in Nassarius reticulatus. J Mar Biol Assoc UK 82:249-255

Besada V, Fumega J, Vaamonde A (2002) Temporal trends of $\mathrm{Cd}, \mathrm{Cu}, \mathrm{Hg}, \mathrm{Pb}$ and $\mathrm{Zn}$ in mussel (Mytilus galloprovincialis) from the Spanish North-Atlantic coast 1991-1999. Sci Total Environ 288:239-253

Bettin C, Oehlmann J, Stroben E (1996) TBT-induced imposex in marine neogastropods is mediated by an increased androgen level. Helgol Meeresunters 50:299-317

Bryan GW, Gibbs PE, Hummerstone LG, Burt GR (1986) The decline of the gastropod Nucella lapillus around SouthWest England: evidence for the effect of tributyltin from antifouling paints. J Mar Biol Assoc UK 66:611-640

Bryan GW, Burt GR, Gibbs PE, Pascoe PL (1993) Nassarius reticulatus (Nassariidae: Gastropoda) as an indicator of tributyltin pollution before and after TBT restrictions. J Mar Biol Assoc UK 73:913-929

Champ MA (2000) A review of organotin regulatory strategies, pending actions, related costs and benefits. Sci Total Environ 258:21-71

Gibbs PE, Bryan GW (1986) Reproductive failure in populations of the dog-whelk, Nucella lapillus, caused by imposex induced by tributyltin from antifouling paints. J Mar Biol Assoc UK 66:767-777

Gibbs PE, Bryan GW (1996) TBT-induced imposex in neogastropod snails: masculinization to mass extinction. In: de Mora SJ (ed) Tributyltin: case study of an environmental contaminant. Cambridge University Press, Cambridge, p 212-236

Huet M, Fioroni P, Oehlmann J, Stroben E (1995) Comparison of imposex response in three prosobranch species. Hydrobiologia 309:29-35

Laughlin RB (1996) Bioaccumulation of TBT by aquatic organisms. In: Champ MA, Seligman PF (eds) Organotin. Chapman \& Hall, London, p 331-355

Laughlin RB, French W, Guard HE (1986) Accumulation of bis(tributyltin) oxide by the marine mussel Mytilus edulis. Environ Sci Technol 20:884-890

Michel P, Averty B (1999) Contamination of French coastal waters by organotin compounds-1997 update. Mar Pollut Bull 38:268-275

Pope N (1998) The bioavailability of sediment-bound tributyltin (TBT). PhD thesis, University of Plymouth

Porte C, Escartín E, García de la Parra LM, Biosca X, Albaiges $\mathrm{J}$ (2002) Assessment of coastal pollution by combined 
determination of chemical and biochemical markers in Mullus barbatus. Mar Ecol Prog Ser 235:205-216

Ruiz JM, Saiz Salinas JI (2000) Extreme variation in the concentration of trace metals in sediments and bivalves from the Bilbao estuary (Spain) caused by the 1989-90 drought. Mar Environ Res 49:307-317

Ruiz JM, Bachelet G, Caumette P, Donard FX (1996) Three decades of tributyltin in the coastal environment with emphasis on Arcachon Bay, France. Environ Pollut 93: 195-503

Ruiz JM, Quintela M, Barreiro R (1998) Ubiquitous imposex and organotin bioaccumulation in gastropods Nucella lapillus (L.) from Galicia (NW Spain): a possible effect of nearshore shipping. Mar Ecol Prog Ser 164:237-244

Sarradin PM, Lapaquellerie Y, Astruc A, Latouche C, Astruc M (1995) Long term behaviour and degradation kinetics of tributyltin in a marina sediment. Sci Total Environ 170: 59-70

Smith BS (1971) Sexuality in the American mud snail, Nassarius obsoletus Say. Proc Malacol Soc Lond 39:377-378

Stroben E, Oehlmann J, Fioroni P (1992a) Hinia reticulata and Nucella lapillus. Comparison of two gastropod tributyltin

Editorial responsibility: Otto Kinne (Editor-in-Chief), Oldendorf/Luhe, Germany bioindicators. Mar Biol 114:289-296

Stroben E, Oehlmann J, Fioroni P (1992b) The morphological expression of imposex in Hinia reticulata (Gastropoda: Buccinidae): a potential indicator of tributyltin pollution. Mar Biol 113:625-636

Sudaryanto A, Takahashi S, Monirith I, Ismail A and 7 others (2002) Asia-Pacific mussel-watch: monitoring of butyltin contamination in coastal waters of Asian developing countries. Environ Toxicol Chem 21:2119-2130

Svavarsson J, Granmo A, Ekelund R, Szpunar J (2001) Occurrence and effects of organotins on adult common whelk (Buccinum undatum) (Mollusca, Gastropoda) in harbours and in a simulated dredging situation. Mar Pollut Bull 42: 370-376

Szpunar J, Schmitt VO, Lobinski R (1996) Rapid speciation of butyltin compounds in sediments and biomaterials by GCAEDm, after microwave-assisted leaching-digestion. J Anal Atomic Spectr 11:193-199

Widdows J, Donkin P, Brinsley MD, Evans SV, Salkeld PN, Franklin A, Law RJ, Waldock MJ (1995) Scope for growth and contaminant levels in North Sea mussels Mytilus edulis. Mar Ecol Prog Ser 127:131-148

Submitted: July 15, 2004; Accepted: October 19, 2004 Proofs received from author: January 24, 2005 